\title{
Investigation of the Regulatory Effects of Saccharin on Cytochrome P450s in Male ICR Mice
}

\author{
Jun Hyeon Jo, ${ }^{1, \dagger}$, Sunjoo Kim ${ }^{1, \dagger}$, Tae Won Jeon ${ }^{2}$, Tae Cheon Jeong ${ }^{3}$ and Sangkyu Lee' \\ 'BK21 Plus KNU Multi-Omics based Creative Drug Research Team, College of Pharmacy, \\ Research Institute of Pharmaceutical Sciences, Kyungpook National University, Daegu, Korea \\ ${ }^{2}$ Toxicological Research Center, Hoseo University, Asan, Korea \\ ${ }^{3}$ College of Pharmacy, Yeungmam University, Gyeongsan, Korea
}

(Received July 22, 2016; Revised August 26, 2016; Accepted August 30, 2016)

\begin{abstract}
Saccharin, the first artificial sweetener, was discovered in 1879 that do not have any calories and is approximately 200 700 times sweeter than sugar. Saccharin was the most common domestically produced sweetener in Korea in 2010, and it has been used as an alternative to sugar in many products. The interaction between artificial sweeteners and drugs may affect the drug metabolism in patients with diabetes, cancer, and liver damage, this interaction has not been clarified thus far. Here, we examined the effects of the potential saccharin-drug interaction on the activities of 5 cytochrome P450 (CYPs) in male ICR mice; further, we examined the effects of saccharin $(4,000 \mathrm{mg} / \mathrm{kg})$ on the pharmacokinetics of bupropion after pretreatment of mice with saccharin for 7 days and after concomitant administration of bupropion and saccharin. Our results showed saccharin did not have a significant effect on the 5 CYPs in the S9 fractions obtained from the liver of mice. In addition, we observed no differences in the pharmacokinetic parameters of bupropion between the control group and the groups pretreated with saccharin and that receiving concomitant administration of saccharin. Thus, our results showed that saccharin is safe and the risk of saccharin-drug interaction is very low.
\end{abstract}

Key words: Artificial sweetener, Saccharin, Cytochrome P450, Pharmacokinetics, Drug interaction

\section{INTRODUCTION}

Food additives such as artificial sweeteners, which enhance the flavor without increasing the calories, are used in some foods and drugs. Saccharin $\left(2 H-1 \lambda^{6}, 2\right.$-benzothiazol-1,1,3trione) (Fig. 1) is the most commonly used artificial sweetener used as an alternative to sugar to sweeten many products, including soft drinks, jams, chewing gum, and drugs (1). Saccharin is the first artificial sweetener and was discovered accidentally by Constantine Fahlberg in 1879. Saccharin has no calories and is 200 to 700 times sweeter than

Correspondence to: Sangkyu Lee, College of Pharmacy, Research Institute of Pharmaceutical Sciences, Kyungpook National University, 80 Daehak-ro, Buk-gu 41566, Korea

E-mail: sangkyu@knu.ac.kr

${ }^{\dagger}$ These authors contributed equally to this study.

This is an Open-Access article distributed under the terms of the Creative Commons Attribution Non-Commercial License (http:// creativecommons.org/licenses/by-nc/3.0) which permits unrestricted non-commercial use, distribution, and reproduction in any medium, provided the original work is properly cited. sugar (2). Previous studies have described the positive and negative effects of saccharin, including its ability to induce hepatic oxidative stress in rats (3) and its anti-hyperglycemic effect in diabetic $o b / o b$ mice (4). Saccharin is not metabolized, and thus, the FDA considers this compound to be safe (2). Previous studies have investigated the effect of artificial sweeteners in patients with diseases such as cancers, hepatotoxicity, migraines, and low birth weight $(5,6)$.

Cytochrome P450 (CYP450) is one of the most important drug-metabolizing enzymes and multiple isoforms of CYP are present in the liver (7). CYP2B6 is a major drugmetabolizing enzyme in humans, which metabolizes 3 15\% of the marketed drugs and accounts for $2 \sim 10 \%$ of the total hepatic CYP (8). CYP2B6 is involved in the elimination of drugs such as antidepressants, antivirals, opioids, and anesthetics (9). CYP2B6 is highly inducible by activation and/or translocation of the constitutive androstane receptor (CAR) NR113 or by protein stabilization $(10,11)$. A previous study showed that incubation of the intestinal cancer cell line LS174T with saccharin for $24 \mathrm{hr}$ did not affect the aryl hydrocarbon receptor (AhR) and glucocorticoid receptor (GR) transcriptional activities (12). In addition, CYP1A1 
mRNA was not induced in primary cultures of human hepatocytes (12). The effect of saccharin on CYP2B, which is a highly inducible enzyme, has not been clarified thus far.

The risks of drug-drug interaction have been reported in many people worldwide. Moreover, the interaction between artificial sweeteners and drugs is important because it may affect drug metabolism in patients with diabetes, cancer, and liver damage. Although artificial sweeteners are commonly used by people, the artificial sweetener-drug interaction has not been clarified to date. Thus, determination of the effect of saccharin on the metabolism of drugs is necessary to develop safe foods and drugs. In this study, we examined the hepatotoxicity of saccharin using the alanine aminotransferase (ALT) and glutathione (GSH) assay and the effect of the potential saccharin-drug interaction on 5 CYP isoforms in male ICR mice. In addition, we examined the effects of treatment with saccharin and bupropion on the pharmacokinetics of the CYP2B substrate.

\section{MATERIALS AND METHODS}

Animals. Specific pathogen-free male ICR mice (28 to $33 \mathrm{~g}$ ) were obtained from Orient (Seoul, Korea). The animals received at 5 weeks of age were acclimated for at least 1 week. Upon arrival, the animals were randomized and housed five per cage. The animal quarters were strictly maintained at a temperature of $23 \pm 3^{\circ} \mathrm{C}$ and $50 \% \pm 10 \%$ relative humidity. A 12-hr light and 12-hr dark cycle was used with an intensity of 150 300 Lux. All animal procedures were followed in accordance with a guideline recommended by the Society of Toxicology (USA) in 1989. This study was approved by the Institutional Review Board of the Kyungpook National University (Daegu, Korea; 20150099).

Animal treatment and preparation of liver S9 fractions. The mice were treated orally with saccharin (Aldrich Chemical Co., Milwaukee, USA) at 250, 1,000, and 4,000 $\mathrm{mg} / \mathrm{kg}$ in saline once daily for 7 consecutive days. Twentyfour hours after the last dose, the animals were killed. Following collection of blood, the livers were removed and homogenized with 4 volumes of ice-cold $0.1 \mathrm{M}$ potassium phosphate buffer, $\mathrm{pH} 7.4$, and then, centrifuged at 9,000 $\mathrm{g}$ for $20 \mathrm{~min}$ at $4^{\circ} \mathrm{C}$. Aliquots of S-9 fractions were stored at $-80^{\circ} \mathrm{C}$ until use. The S-9 fractions were prepared from the liver for determining the CYP activities. Protein content in the $\mathrm{S} 9$ fractions was determined using bovine serum albumin as a standard.

Hepatotoxicity assay. For determining the activities of ALT (Asan Pharm. Co. Hwasung, Korea), we centrifuged the blood obtained from the mice at $2,500 \mathrm{~g}$ for $15 \mathrm{~min}$ at $4^{\circ} \mathrm{C}$. The activities of enzymes were determined according to an instruction manual prepared by the manufacturer. The levels of reduced GSH was determined using Ellman's method (13).

CYP activities assay. S-9 fractions were prepared from livers to determine the activities of CYP-associated monooxygenase. Each assay contained $0.1 \mathrm{M}$ potassium phosphate buffer ( $\mathrm{pH} 7.4$ ), cocktail probe substrates, S9 fraction $(20 \mu \mathrm{L})$, and a NADPH-generating system (NGS) containing $0.1 \mathrm{M}$ glucose 6-phosphate, $10 \mathrm{mg} / \mathrm{mL} \beta-\mathrm{NADPH}$, and $1.0 \mathrm{U} / \mathrm{mL}$ glucose-6-phosphate dehydrogenase, in a final volume of $100 \mu \mathrm{L}$. The probe substrate mixture contained $80 \mu \mathrm{M}$ phenacetin for CYP1A2, $20 \mu \mathrm{M}$ bupropion for CYP2B, $20 \mu \mathrm{M}$ omeprazole for CYP2C, $5.0 \mu \mathrm{M}$ dextromethorphan for CYP2D, and $5 \mu \mathrm{M}$ midazolam for CYP3A (10). Following a $5 \mathrm{~min}$ preincubation period in the absence of probe substrate mixture, the reaction mixture was incubated for $60 \mathrm{~min}$ at $37^{\circ} \mathrm{C}$, and the reaction was stopped by adding $200 \mu \mathrm{L}$ acetonitrile (ACN) containing $0.1 \%$ formic acid and $5 \mu \mathrm{M}$ reserpine (as an internal standard, IS). After mixing and centrifuging at $13,000 \mathrm{~g}$ for $5 \mathrm{~min}$, a $10 \mu \mathrm{L}$ aliquot was injected onto the liquid chromatography tandem mass spectrometry (LC-MS/MS) system.

Pharmacokinetic study. Twelve male ICR mice (30 \pm $2 \mathrm{~g})$ were randomly divided into control and saccharin group $(n=3)$. The mice in the control group received intraperitoneal (i.p.) administration of saline with bupropion (20 $\mathrm{mg} / \mathrm{kg}$ ) and oral administration of saccharin $(4,000 \mathrm{mg} / \mathrm{kg})$. Bupropion was administered $5 \mathrm{~min}$ after administration of saccharin. Blood samples were collected from the tail vein in heparinized capillary tubes at $5,10,15,30,60,120$, and $240 \mathrm{~min}$ after oral administration of bupropion. The samples were immediately centrifuged at $13,000 \mathrm{rpm}$ for 10 min, and $10 \mu \mathrm{L}$ plasma was obtained from each sample.

Plasma samples were mixed with $90 \mu \mathrm{L}$ ACN containing $0.1 \%$ formic acid, and then, the IS solution $(5 \mu \mathrm{M}$ reserpine) was added. After mixing and centrifuging at 13,000 rpm for $10 \mathrm{~min}$ at $4^{\circ} \mathrm{C}$, we separated $90 \mu \mathrm{L}$ of the supernatant. The supernatants were transferred to autosampler vials, and $5 \mu \mathrm{L}$ aliquots were injected into the LC system. The concentration of bupropion in calibration standards were $0 \sim 6,000 \mathrm{ng} / \mathrm{mL}$. The calibration curves were constructed by plotting the peak-area ratio of bupropion and the IS.

Analysis using the LC-MS/MS system. All measurements were performed using a LC-MS/MS unit in the selective reaction monitoring (SRM) mode. We used a TSQ Vantage triple quadrupole mass spectrometer with an HESIII spray source and coupled to an Accela ${ }^{\mathrm{TM}}$ LC system (Thermo Fisher Scientific Inc., MA, USA). Electrospray ionization was performed in the positive mode at a spray voltage of $3500 \mathrm{~V}$. Nitrogen sheath and auxiliary gas was used at 45 and 20 (arbitrary units), respectively. The vaporizer and capillary temperatures were set at $150^{\circ} \mathrm{C}$ and $300^{\circ} \mathrm{C}$. 


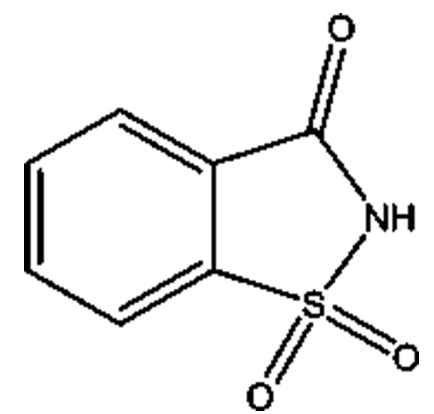

Fig. 1. Chemical structure of saccharin.

Data were analyzed using the Xcalibur software (Thermo Fisher Scientific Inc.).

The CYP activities were measured using high-performance liquid chromatography (HPLC) by using an Inertsil ODS-3 column $(3 \mu \mathrm{m}, 2.1 \times 150 \mathrm{~mm}$, GL Sciences Inc., Tokyo, Japan) and a guard C18 column $(2 \mu \mathrm{m}, 2.1 \mathrm{~mm}$ i.d., Phenomenex, CA, USA). The mobile phase consisted of acetonitrile (mobile phase A) and water (mobile phase B) both containing $0.1 \%$ formic acid at a flow rate of $0.22 \mathrm{~mL} /$ $\min$ at $30^{\circ} \mathrm{C}$. The gradient conditions were as follows: 5 95\% A for $0 \sim 7.0 \mathrm{~min}, 95 \%$ for $7.0 \sim 8.0 \mathrm{~min}, 95 \sim 5 \%$ for $8.0 \sim$ $8.5 \mathrm{~min}$, and $5 \%$ for $8.5 \sim 12 \mathrm{~min}$. SRM was performed by monitoring the precursor-product ion transition of $\mathrm{m} / \mathrm{z}$ $152.0 \rightarrow 110.0$ for acetaminophen (collision energy [CE]: $15 \mathrm{eV}), m / z 256.0 \rightarrow 238.0$ for hydroxy bupropion (CE: $15 \mathrm{eV}$ ), $m / z \quad 362.0 \rightarrow 214.0$ for hydroxyl omeprazole (CE: $11 \mathrm{eV}), m / z 258.0 \rightarrow 157.0$ for dextrorphan $(\mathrm{CE}: 37 \mathrm{eV})$, $m / z 342.0 \rightarrow 203.0$ for 1 '-hydroxy midazolam (CE: $15 \mathrm{eV})$, and $m / z 609.4 \rightarrow 174.1$ for reserpine (CE: $42 \mathrm{eV}$ ).

The LC-MS/MS conditions used for determining the pharmacokinetics of saccharin were the same as those used for determining the CYP activities. We used the $\mathrm{ACE}^{\circledR} 5$ C18 column $(5 \mathrm{~mm}, 50 \times 2.1 \mathrm{~mm}$, Advanced Chromatography Technologies, Aberdeen, UK) and a guard C18 column ( $2 \mathrm{~mm}, 2.1 \mathrm{~mm}$ i.d., Phenomenex) for the LC separation. The mobile phase consisted of acetonitrile (mobile phase A) and water (mobile phase $\mathrm{B}$ ) both containing $0.1 \%$ formic acid at a flow rate of $0.22 \mathrm{~mL} / \mathrm{min}$ at $30^{\circ} \mathrm{C}$. The gradient conditions were as follows: $5 \% \mathrm{~A}$ for $0 \sim 0.5 \mathrm{~min}, 5 \sim 95 \% \mathrm{~A}$ for $0.5 \sim 1.5 \mathrm{~min}, 95 \%$ for $1.5 \sim 3.0 \mathrm{~min}, 95 \sim 5 \%$ for $3.0 \sim 3.3$ $\mathrm{min}$, and $5 \%$ for $3.3 \sim 5.0 \mathrm{~min}$. SRM was performed by monitoring the precursor-product ion transition of $\mathrm{m} / \mathrm{z} 240.1 \rightarrow$ 184.0 for bupropion and $\mathrm{m} / \mathrm{z} 609.4 \rightarrow 174.1$ for reserpine (internal standard) with the CE of 19 and $42 \mathrm{eV}$, respectively.

Pharmacokinetic parameters and statistics. The pharmacokinetic parameters were determined using the standard non-compartmental model. Serum area under the curve (AUC) was calculated using WinNonlin (version 1.1, Scientific Consulting, KY, USA) with a log-linear trapezoidal method. The mean value \pm standard error (SE) was determined for each treatment group of a given experiment. Dunnett's $t$-test was used to compare statistical significance of data. The significant value at either $P<0.05(*)$ was represented as asterisks.

\section{RESULTS}

Effects of saccharin on hepatotoxicity and drug metabolizing enzymes. To investigate the toxic effect of saccharin, we determined changes in body and liver weights after treatment with saccharin $(0,250,1,000$, and 4,000 mg/ $\mathrm{kg}$ ) by oral gavage for 7 days. The body and liver weights did not change after treatment with saccharin (Table 1). The serum ALT and liver GSH levels in the saccharin group, which were used as indicators of hepatotoxicity, was not increased significantly compared to those in the vehicle control groups.

To investigate the inhibitory effects of saccharin on the activities of CYP isoforms, we performed CYP activity assays using a cocktail of probe substrates coupled with an LC-MS/MS system. Compared to the control, saccharin had no significant regulatory effect on all the CYPs in the S9 fractions obtained from the liver of the male ICR mice (Fig. 2).

Pharmacokinetic effect of saccharin on ICR mice. The main pharmacokinetic parameters after administration of bupropion determined using non-compartmental analysis are summarized in Table 2. The representative bupropion concentration vs. time profiles of 3 mice are shown in Fig. 3. To investigate the effects of saccharin on the metabolic

Table 1. Change of body weight and hepatotoxicity parameters after oral administration of saccharin for 7 consecutive days to male ICR mice

\begin{tabular}{ccccc}
\hline \hline Dose $(\mathrm{mg} / \mathrm{kg})$ & Body weight $(\mathrm{g})$ & Liver weight $(\mathrm{g})$ & ALT $($ Karmen) & GSH (\%) \\
\hline 0 & $31.7 \pm 0.6$ & $1.9 \pm 0.1$ & $105.6 \pm 7.0$ & $100.0 \pm 12.0$ \\
250 & $33.5 \pm 1.6$ & $1.9 \pm 0.2$ & $123.1 \pm 8.7$ & $121.4 \pm 8.8$ \\
1000 & $32.9 \pm 0.5$ & $1.9 \pm 0.1$ & $135.7 \pm 36.0$ & $94.5 \pm 5.7$ \\
4000 & $33.0 \pm 0.6$ & $2.1 \pm 0.0^{*}$ & $129.6 \pm 22.4$ & $122.6 \pm 1.9$ \\
\hline
\end{tabular}

Male ICR mice were treated orally with $250,1,000$, and $4,000 \mathrm{mg} / \mathrm{kg}$ of saccharin in saline for 7 days. Animals were subjected to necropsy $24 \mathrm{hr}$ after the last treatment. Each value represents the mean \pm standard error (SE) of 3 5 animals. The asterisks indicate the values significantly different from the control at either $P<0.05\left(^{*}\right)$. 

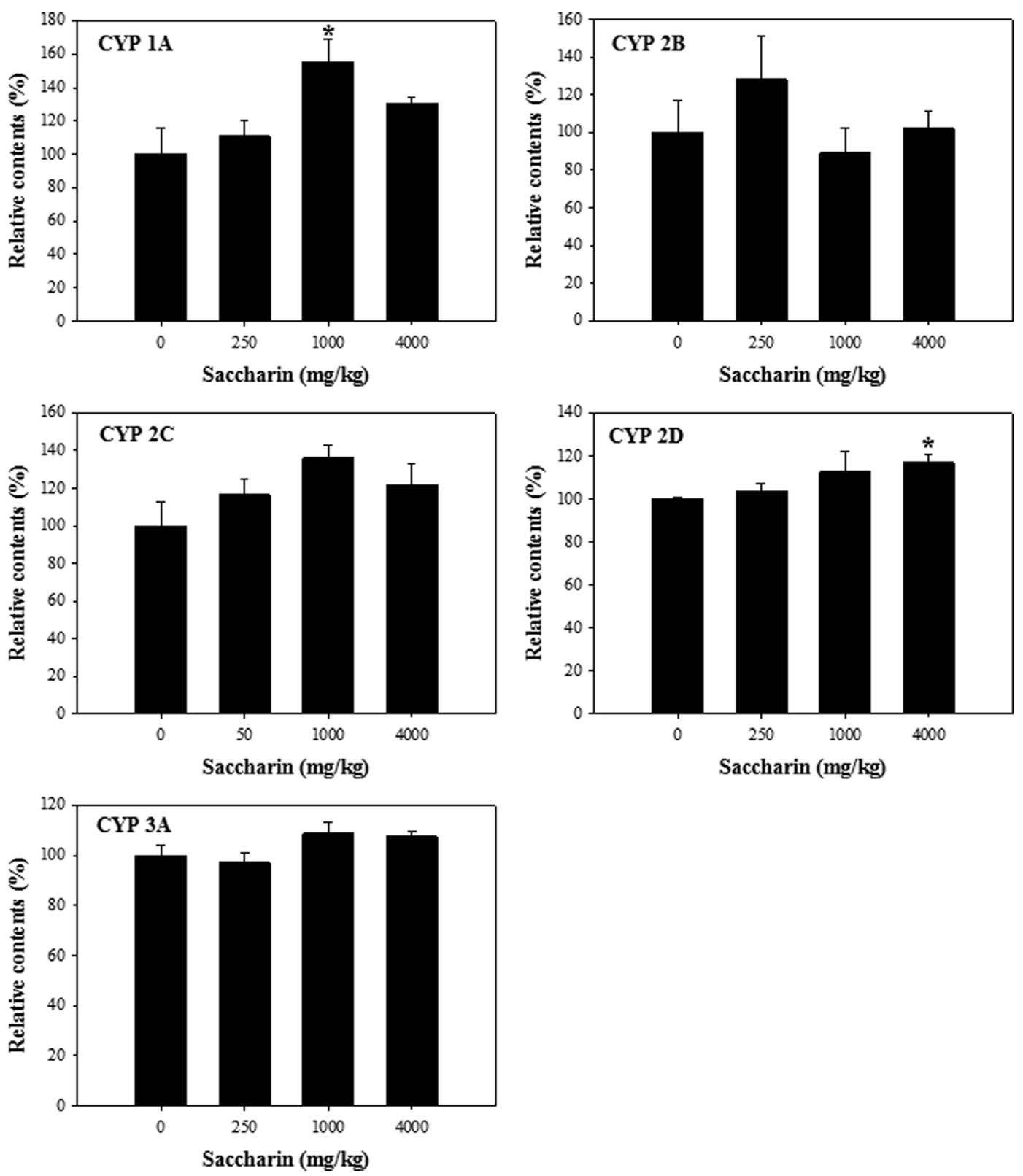

Fig. 2. Cytochrome P450 (CYP) activities in liver $S 9$ fractions of male ICR mice after administration of saccharin $(0,250,1,000$, and $4,000 \mathrm{mg} / \mathrm{kg}$ ) for 1 week. ${ }^{*} P<0.05$.

Table 2. Plasma concentration-time curve of bupropion after pretreatment with saccharin $(4,000 \mathrm{mg} / \mathrm{kg})$ for 7 days and after concomitant administration of saccharin and bupropion to male ICR mice

\begin{tabular}{crcccc}
\hline \hline \multirow{2}{*}{ Saccharin $(\mathrm{mg} / \mathrm{kg})$} & \multicolumn{4}{c}{ Pharmacokinetic parameters } \\
\cline { 3 - 6 } & & $\mathrm{T}_{\max }(\mathrm{min})$ & $\mathrm{C}_{\max }(\mathrm{mg} / \mathrm{mL})$ & $\mathrm{AUC}(\mathrm{mg} \cdot \mathrm{min} / \mathrm{mL})$ & $\mathrm{T}_{1 / 2}(\mathrm{~min})$ \\
\hline 7 Days & 0 & $30.0 \pm 21.2$ & $0.4 \pm 0.1$ & $50.1 \pm 13.6$ & $110.3 \pm 26.9$ \\
pretreatment & 4,000 & $13.3 \pm 2.4$ & $0.6 \pm 0.1$ & $66.2 \pm 11.6$ & $77.6 \pm 4.9$ \\
\hline Single & 0 & $15.0 \pm 0.0$ & $0.7 \pm 0.2$ & $81.9 \pm 11.6$ & $68.3 \pm 18.7$ \\
co-treatment & 4,000 & $20.0 \pm 7.1$ & $0.6 \pm 0.2$ & $68.5 \pm 4.2$ & $112.9 \pm 81.2$ \\
\hline
\end{tabular}

Male ICR mice were treated orally with 0 and $4,000 \mathrm{mg} / \mathrm{kg}$ of saccharin in water for 7 consecutive or received a single oral administration. Each value represents the mean \pm standard error (SE) of 3 5 animals. 


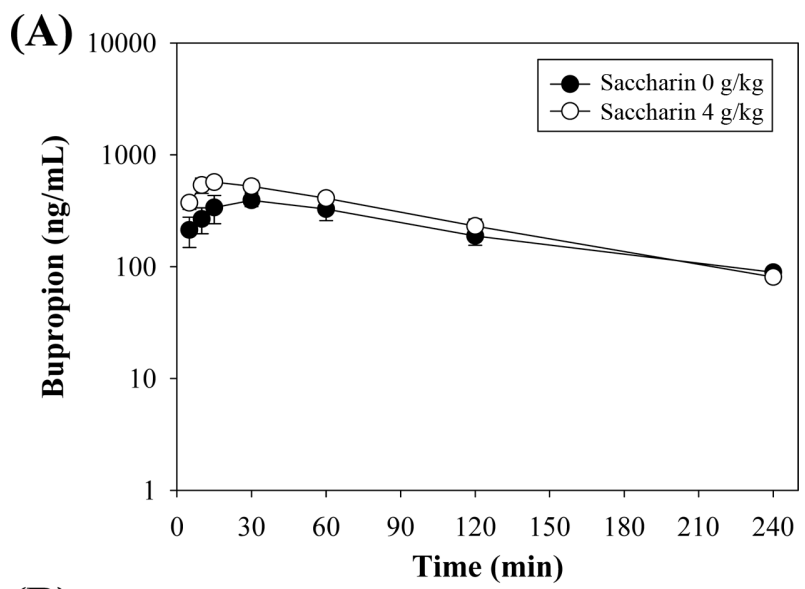

(B)

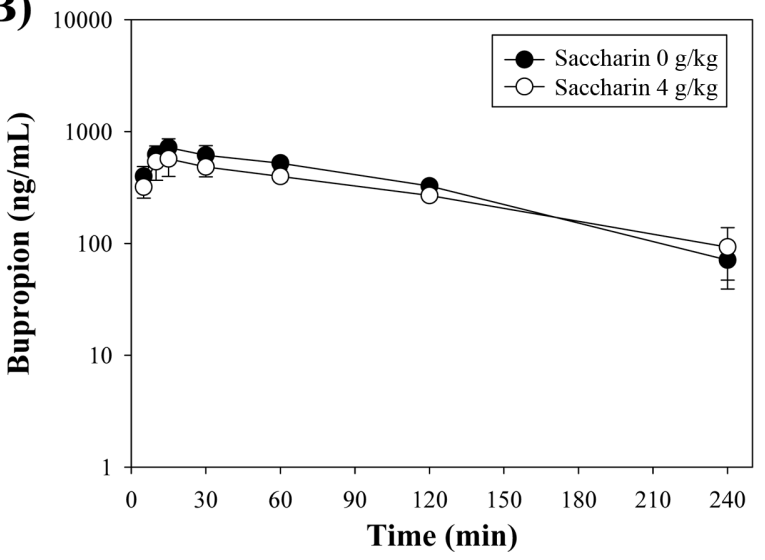

Fig. 3. Time-dependent plasma concentration of bupropion $(20 \mathrm{mg} / \mathrm{kg}$, i.p.) after pretreatment with oral administration of saccharin ( 0 and $4,000 \mathrm{mg} / \mathrm{kg}$, p.o.) for 7 days (A) and after concomitant administration of saccharin ( 0 and $4,000 \mathrm{mg} / \mathrm{kg}$, p.o.) (B) in male ICR mice.

activity of CYP2B, we determined the plasma concentration of bupropion in the mouse after administration of a single dose of bupropion (i.p., $20 \mathrm{mg} / \mathrm{kg}$ ) after co-treatment or pretreatment with saccharin (p.o., $4,000 \mathrm{mg} / \mathrm{kg}$ ). For pretreatment, the mice were orally administered saccharin for 7 consecutive days and then received intraperitoneal (i.p.) administration of bupropion $24 \mathrm{hr}$ after the last administration of saccharin. For co-treatment, the mice received oral administration of $4,000 \mathrm{mg} / \mathrm{kg}$ of saccharin and, after $5 \mathrm{~min}$, received bupropion. Blood samples were collected at 5, 10, $15,30,60,120$, and 240 min after dosing.

To determine whether saccharin induced CYP2B, we pretreated the mice orally with saccharin $(4,000 \mathrm{mg} / \mathrm{kg})$ for 7 days. Compared to the control group, the saccharin group showed no significant change in the pharmacokinetic parameters of bupropion. In addition, concomitant administration of saccharin and bupropion showed no significant differences in the pharmacokinetic parameters of bupropion, which indicates that saccharin had no inhibitory effect on the CYP2B activity in vivo. Our results showed that administra- tion of saccharin at a dose 200-fold higher than the acceptable daily intake (ADI) for sub-acute administration had no effect on the CYP2B activity. Moreover, concomitant administration of saccharin and bupropion had no inhibitory effect on the CYP2B activity and it did not change the pharmacokinetic parameters of bupropion.

\section{DISCUSSION}

In 2005, a study was performed in Korea to evaluate the safety of artificial sweeteners and to determine the estimate the daily intake (EDI) of saccharin (14). For $90^{\text {th }}$ percentile consumers, the EDI of saccharin was $2.0 \mathrm{mg} / \mathrm{kg}$ (body weight)/day, which was $40.7 \%$ of the ADI set by the Joint FAO/WHO Expert Committee on Food Additives (JECFA). In recent survey, the EDI of most Korean consumers was no greater than $20 \%$ of their corresponding ADI (15). This consumption pattern indicated that saccharin was consumed at a dose lower than the ADI not only in Korea but also in other countries. A study on the Belgian population older than 15 years indicated that the $95^{\text {th }}$ percentile $(\mathrm{p} 95)$ was $17 \%$ for saccharin of the respective ADI (16). The level of mean daily intakes of saccharin corresponds to $17 \%$ of the corresponding ADI value in Germany (17). Previous studies indicate that the EDIs of saccharin in many countries might be significantly lower than ADI set by the JECFA.

Saccharin as a representative artificial sweetener might not be associated with serious adverse effects by food-drug interaction. Saccharin has no regulatory effects on the activities of liver cytochromes, and the amount of saccharin in foods has been strictly regulated by the government agencies worldwide. Although our results indicate that saccharin is associated with a low risk of interaction with drugs, we should be aware of the possibility of food-drug interaction after chronic exposure to saccharin in foods. The rate of consumption of saccharin has continuously increased over the years among consumers of syrup and beverages and has reached $60 \%$ of the ADI in the last $1 \sim 2$ years (7). Furthermore, the safety and possibility of saccharin-drug interaction should be studied in young or infant animal models to predict the effects of saccharin on babies.

\section{ACKNOWLEDGMENTS}

This work was supported by Korea Institute of Planning and Evaluation for Technology in Food, Agriculture, Forestry and Fisheries (IPET) through Export Promotion Technology Development Program, funded by Ministry of Agriculture, Food and Rural Affairs (MAFRA) (grant number 316017-3).

\section{REFERENCES}

1. Whitehouse, C.R., Boullata, J. and McCauley, L.A. (2008) 
The potential toxicity of artificial sweeteners. $A A O H N J ., \mathbf{5 6}$, 251-259.

2. FDA Office of Public Affairs (2006) Artificial sweeteners: no calories...sweet! FDA Consum., 40, 27-28.

3. Amin, K.A. and AlMuzafar, H.M. (2015) Alterations in lipid profile, oxidative stress and hepatic function in rat fed with saccharin and methyl-salicylates. Int. J. Clin. Exp. Med., 8, 6133-6144.

4. Bailey, C.J., Day, C., Knapper, J.M., Turner, S.L. and Flatt, P.R. (1997) Antihyperglycaemic effect of saccharin in diabetic ob/ob mice. Br. J. Pharmacol., 120, 74-78.

5. Qurrat-ul-Ain and Khan, S.A. (2015) Artificial sweeteners: safe or unsafe? J. Pak. Med. Assoc., 65, 225-227.

6. Andreatta, M.M., Munoz, S.E., Lantieri, M.J., Eynard, A.R. and Navarro, A. (2008) Artificial sweetener consumption and urinary tract tumors in Cordoba, Argentina. Prev. Med., 47, 136-139.

7. Rendic, S. (2002) Summary of information on human CYP enzymes: human P450 metabolism data. Drug Metab. Rev., 34, 83-448.

8. Wang, H.B. and Tompkins, L.M. (2008) CYP2B6: New insights into a historically overlooked cytochrome $\mathrm{P} 450$ isozyme. Curr. Drug Metab., 9, 598-610.

9. Mo, S.L., Liu, Y.H., Duan, W., Wei, M.Q., Kanwar, J.R. and Zhou, S.F. (2009) Substrate specificity, regulation, and polymorphism of human cytochrome P450 2B6. Curr. Drug Metab., 10, 730-753.

10. Sim, J., Nam, W., Lee, D., Lee, S., O, H., Joo, J., Liu, K.H., Han, J.Y., Ki, S.H., Jeong, T.C., Lee, T. and Lee, S. (2015)
Selective induction of hepatic cytochrome P450 2B activity by leelamine in vivo, as a potent novel inducer. Arch. Pharm. Res., 38, 725-733.

11. Kawamoto, T., Sueyoshi, T., Zelko, I., Moore, R., Washburn, K. and Negishi, M. (1999) Phenobarbital-responsive nuclear translocation of the receptor CAR in induction of the CYP2B gene. Mol. Cell. Biol., 19, 6318-6322.

12. Kamenickova, A., Pecova, M., Bachleda, P. and Dvorak, Z. (2013) Effects of artificial sweeteners on the AhR- and GRdependent CYP1A1 expression in primary human hepatocytes and human cancer cells. Toxicol. In Vitro, 27, 22832288 .

13. Ellman, G.L. (1959) Tissue sulfhydryl groups. Arch. Biochem. Biophys., 82, 70-77.

14. Chung, M.S., Suh, H.J., Yoo, W., Choi, S.H., Cho, Y.J., Cho, Y.H. and Kim, C.J. (2005) Daily intake assessment of saccharin, stevioside, D-sorbitol and aspartame from various processed foods in Korea. Food Addit. Contam., 22, 1087-1097.

15. Ha, M.S., Ha, S.D., Choi, S.H. and Bae, D.H. (2013) Assessment of Korean consumer exposure to sodium saccharin, aspartame and stevioside. Food Addit. Contam. Part A Chem. Anal. Control Expo. Risk Assess., 30, 1238-1247.

16. Huvaere, K., Vandevijvere, S., Hasni, M., Vinkx, C. and Van Loco, J. (2012) Dietary intake of artificial sweeteners by the Belgian population. Food Addit. Contam. Part A Chem. Anal. Control Expo. Risk Assess., 29, 54-65.

17. Bar, A. and Biermann, C. (1992) Intake of intense sweeteners in Germany. Z. Ernahrungswiss., 31, 25-39. 